\title{
BMJ Open Multifaceted self-management interventions for older women with urinary incontinence: a systematic review and narrative synthesis
}

\author{
Yu Fu, ${ }^{\oplus 1}$ E Andrea Nelson, ${ }^{2}$ Linda McGowan ${ }^{1}$
}

To cite: Fu Y, Nelson EA, McGowan L. Multifaceted self-management interventions for older women with urinary incontinence: a systematic review and narrative synthesis. BMJ Open 2019;9:e028626. doi:10.1136/ bmjopen-2018-028626

- Prepublication history and additional material for this paper are available online. To view these files, please visit the journal online (http://dx.doi org/10.1136/bmjopen-2018028626).

Received 17 December 2018 Revised 17 July 2019 Accepted 23 July 2019
Check for updates

(C) Author(s) (or their employer(s)) 2019. Re-use permitted under CC BY-NC. No commercial re-use. See rights and permissions. Published by BMJ.

${ }^{1}$ School of Healthcare, University of Leeds, Leeds, UK

${ }^{2}$ School of Health and Life Sciences, Glasgow Caledonian University, Glasgow, UK

Correspondence to DrYu Fu; y.fu@leeds.ac.uk

\section{ABSTRACT}

Objective To synthesise the evidence for the multifaceted self-management interventions for older women with urinary incontinence $(\mathrm{UI})$ and to understand the outcomes associated with these interventions.

Design A systematic review and narrative synthesis to identify randomised controlled trials that investigated the effect of multifaceted self-management interventions for older women with UI.

Methods MEDLINE, PsycINFO, EMBASE, The Cochrane Library, CINAHL and Applied Social Sciences Index and Abstracts databases were searched (January 1990 to May 2019) using a systematic search strategy, complemented by manually screening the reference lists and citation indexes. Study selection, data extraction and risk of bias assessment were undertaken independently. A narrative synthesis was undertaken in which studies, interventions and outcomes were examined based on the intervention components. The effect size and $95 \% \mathrm{Cl}$ were estimated from each study.

Results A total of 13147 citations were identified and 16 studies were included. There was no study rated as of high quality. Three types of multifaceted interventions were found: those that had an element of pelvic floor muscle exercises (PFME), those with bladder retraining and some with combination behavioural interventions. Outcome measures varied across studies. A statistically significant improvement in incontinence symptoms was reported in the intervention group compared with the control in 15 studies.

Conclusion Multifaceted interventions that included PFME, bladder retraining or combination behavioural techniques appear to be useful in some settings for $\mathrm{UI}$ management in older women, but the quality of the evidence was poor and unclear. There was insufficient evidence to determine whether any of the combination of components is superior to others in improving UI symptoms. There is a need for high-quality studies to confirm the effectiveness of these interventions and to identify comparative effectiveness.

\section{PROSPERO registration number CRD42018104010.}

\section{BACKGROUND}

Urinary incontinence (UI) is 'the complaint of any involuntary leakage of urine'. ${ }^{1}$ It has been estimated that, in the UK, over 14 million

\section{Strengths and limitations of this study}

- Comprehensive searching using a sensitive search strategy identified a large number of potentially relevant reports.

- Tailored self-management intervention comprising multicomponent is needed for older women with incontinence.

- Multifaceted interventions that included pelvic floor muscle exercises, bladder retraining or combination techniques appear to be useful in Urinary incontinence management.

- No study was rated as of high quality on multifaceted self-management interventions for older women with incontinence, hence we have low confidence in the robustness of these findings.

- Insufficient evidence to determine whether any of the combination of components is superior to others in improving symptoms.

people are affected by bladder control problems. ${ }^{2} \mathrm{UI}$ is more common in women aged 55 or above, ${ }^{3}$ and estimates of the point prevalence range from $35 \%$ to $60 \%$, increasing with age. ${ }^{4-6}$ While not life-threatening, UI has physical, psychosocial and emotional consequences for individuals and their families, with considerable impacts on society. ${ }^{7-9}$ There is limited up-to-date information on the cost of managing UI in the UK, the estimated annual cost (related to 1999/2000) to the UK National Health Service of treating clinically significant UI is $£ 536$ million ( $£ 233$ million for women). ${ }^{10}$

Despite the substantial impact on individual's quality of life, UI remains under-reported and undertreated due to stigma and embarrassment. ${ }^{11}{ }^{12}$ Evidence has suggested that one-third of women with UI consult a doctor in European countries such as France, Germany, Spain and the UK, and only $20 \%-25 \%$ of those experiencing significant clinical symptoms seek care and less than half of them receive treatment. ${ }^{13}{ }^{14}$ Untreated UI 
is not only an unmet health need but is also associated with falls and fractures (associated with needing to get to a bathroom frequently or urgently) as well as depression in older people. ${ }^{15}$ The main reasons for not accessing medical care are feeling embarrassed, poor awareness or low expectations of treatments, and perceiving UI as an inevitable consequence of ageing. ${ }^{16-20}$ Many individuals try to cope and self-manage on their own with variable success. $^{21-24}$

Since the advent of systematically developed chronic disease self-management programmes, ${ }^{25}$ many self-management interventions have been developed to support people with long-term conditions. Participants report a range of positive outcomes including a high degree of self-efficacy, improved ability to undertake daily activities and reduced fatigue and depression. ${ }^{26-36}$ Self-management is considered to be a multidimensional construct ${ }^{37}$ and defined as an intervention designed to develop individuals' knowledge, skills or psychological and social resources and their ability to manage their health condition and consequences, through education, training and support. ${ }^{38-40}$ However, older women living with UI remain a neglected group, because it is a hidden health problem, ${ }^{41}{ }^{42}$ and the high risk of having multiple comorbidities in older people. ${ }^{43}$ This highlights the potential benefit of tailored self-management advice and support for older women living with UI.

Self-management interventions for UI are often complex and no single procedure or intervention is optimal for all people. For example, systematic reviews of single faceted interventions can only make tentative conclusions that pelvic floor muscle exercises (PFME) or bladder training may be helpful for women with UI. ${ }^{44} 45$ A multifaceted intervention comprising management of physical and psychological impact offers the possibility of tailoring treatment to the desires and needs of the individual. ${ }^{46}$ The success of self-management requires the development of skills that allow individuals to effectively manage their symptoms, behaviours and emotions simultaneously. Also, considering the potential comorbidities in older people, ${ }^{47}$ a multifaceted self-management intervention is likely to be more effective than a single component for older women living with UI. ${ }^{49}$ Although certain self-management strategies seem effective in addressing frequency and amount of women's leakage when compared with controls, for example, PFME, timed voiding and toilet habit training, ${ }^{23245051}$ there is no synthesis of randomised controlled trials (RCTs) of multifaceted self-management interventions for older women (aged 55 or over) with UI in a systematic manner, hence this review. The aim of this review was, therefore, to synthesise multifaceted self-management interventions for older women living with UI and to understand the outcomes associated with these interventions.

\section{METHODS}

This systematic review was undertaken following the Centre for Reviews and Dissemination's (CRD's) guidance $^{52}$ and the Preferred Reporting Items for Systematic Reviews and Meta-Analyses statement. ${ }^{5354}$

\section{Criteria for considering studies for this review \\ Type of studies}

In evaluating the extent to which self-management interventions are effective in this group, RCTs will provide high-quality evidence and allow estimation of effect sizes. ${ }^{55}$ RCTs were considered that included self-management interventions for managing urine leakage compared with any other form of treatment such as other self-management interventions, pharmacological treatment, usual care and/or waiting list controls.

\section{Type of participants}

Women 55 years of age or over who are cognitively intact with a symptom of any involuntary leakage of urine that is not caused by neurological diseases affecting the brain and spinal cord, such as Parkinson's disease, or requires cancer treatment, such as bladder cancer.

\section{Type of interventions}

Multifaceted self-management interventions, such as exercises and education, delivered to older women with UI with an aim to develop individual's ability to manage the symptoms, treatment, physical and psychosocial consequences, and lifestyle changes. ${ }^{31}$ Trials were eligible for inclusion if the intervention involved at least two self-management methods, such as PFME and general exercise, delivered to women with an aim to help them manage their UI and associated problems.

\section{Type of outcome measures}

There are inconsistent recommendations on core outcome domains in studies of interventions for UI. ${ }^{56}$ No core outcome sets were identified in Core Outcome Measures in Effectiveness Trials. For this review, therefore, trials were eligible for inclusion regardless of outcomes measured or reported.

\section{Search methods for identification of studies}

Six databases (MEDLINE, PsycINFO, EMBASE, The Cochrane Library, CINAHL and Applied Social Sciences Index and Abstracts) were searched from January 1990 to May 2019. Detailed search strategies were developed for each database. These were based on the search strategy developed for MEDLINE (OVID) (see online supplementary 1) and refined in consultation with the research team and an information scientist. A range of keywords and subject headings representing self-management and UI were used, aiming to maximise the retrieval of relevant records. The Cochrane Highly Sensitive Search Strategy for identifying RCTs was also linked to the search as a means of retrieving RCTs. ${ }^{57}$ Reference lists and citation indexes of relevant articles were scrutinised. Only records published after 1990 (the prototype for the chronic 
disease self-management programme was completed in 1996) and in the English language (no resource available for translation) were searched.

\section{Selection of studies}

Identified citations were exported to EndNote V.X6 ${ }^{58}$ for deduplication and review. Record titles and abstracts were screened independently by two review authors. Full paper copies of studies were retrieved where citations appeared to meet the eligibility criteria or where a decision to exclude could not be made on the information provided. Whenever there was a disagreement between two researchers (YF and LM) relating to the inclusion of a given study, a third researcher (EAN) was consulted until consensus was reached.

\section{Data extraction}

Data were extracted on the characteristics of study participants, intervention details, control groups, outcome measures and results, using a data extraction sheet piloted on two retrieved study reports. All review authors were involved in the piloting and modification process. Accuracy and consistency were monitored through random double-extraction of trials by LM. Any differences were resolved by discussion. Where a trial appeared to have multiple citations then original authors were contacted for clarification. With no replies received, a decision was made to use all information from multiple citations as from one trial.

\section{Assessment of risk of bias}

Risk of bias assessment was undertaken in accordance with the Cochrane Handbook for Systematic Review of Interventions. ${ }^{59} \mathrm{~A}$ summary of the risk of bias across studies was given, where a low risk of bias was rated when all domains were at low risk, an unclear risk of bias when one or more domains were at unclear risk, and a high risk of bias when one or more domains were at high risk. Risk of bias assessment was undertaken independently by two review researchers (YF and LM). Whenever there was a disagreement, a third researcher (EAN) was consulted until consensus was reached.

\section{Data synthesis}

The data synthesis was undertaken following CRD's guidance. ${ }^{60}$ The effect size and $95 \%$ CI were estimated for the primary outcome of each study. ${ }^{57} \mathrm{~A}$ narrative synthesis was undertaken following Popay et al's approach to conducting narrative synthesis in a systematic and transparent manner, ${ }^{61}$ which focuses on the effects of the interventions and how these interventions could lead to outcomes. Studies, interventions and associated outcomes were examined and regrouped based on the components of the self-management interventions. Shared themes and tabulated summaries were presented in which results and significance reported were indicated.

\section{Patient and public involvement}

A project advisory group comprising three older women (aged 55 or over) living with UI and one nurse working in the community continence clinic had been set up prior to the commencement of this review, to ensure their valuable input on the study design. YF led the meeting that was facilitated by LM/EAN every 6 months. Group members were provided with background information and clinical guideline in the UI assessment and management and consulted for their current experiences and expectations of managing the UI. They all highlighted the need for evidence-based practice for older women and perceived synthesis of existing RCTs being necessary to inform such evidence. Process of conducting systematic reviews was clearly presented to all group members. As this study progressed, they were also invited to review and comment on results of study selection, risk of bias assessment and data synthesis.

\section{RESULTS}

\section{Selection of studies}

A total of 13561 citations were yielded by the initial search. Following the screening of titles and abstracts, 64 records were retrieved in full text, and 45 were further excluded as they only included single component interventions and/or involved participants who were not women aged 55 or above. In total, 19 citations were included representing 16 RCTs, as three trials had multiple citations (see figure 1).

\section{Risk of bias}

Risk of bias figure was completed for each included study (figure 2). Eleven studies were rated as high risk of bias, five were at unclear risk of bias and one was at low risk of bias. Most studies reported adequate information on methods used to generate the randomisation sequence, but commonly did not report on allocation concealment and blinding, leading to their being assessed as unclear risk of bias. For incomplete outcome data, a high risk of bias was noted if the last observation was carried forward was used to handle missing data. Selective outcome reporting bias was identified in four studies meaning that not all measured outcomes were reported. High and unclear risk of bias in most of the included studies was identified as the main barrier to the evaluation of the effectiveness of self-management interventions for women with UI.

\section{Study characteristics}

The 16 included studies were conducted in the USA, Japan, UK, Canada, France, Hong Kong and Turkey. Of 16 studies, nine were undertaken in community centres $^{22} 49{ }^{62-68}$ and seven in clinics ${ }^{69-74}$ or nursing homes. ${ }^{75}$ A total of 3237 women aged 55 or over with stress UI, urge UI, mixed UI and overactive bladder were recruited to component trials. Multifaceted self-management interventions comprised education, information 


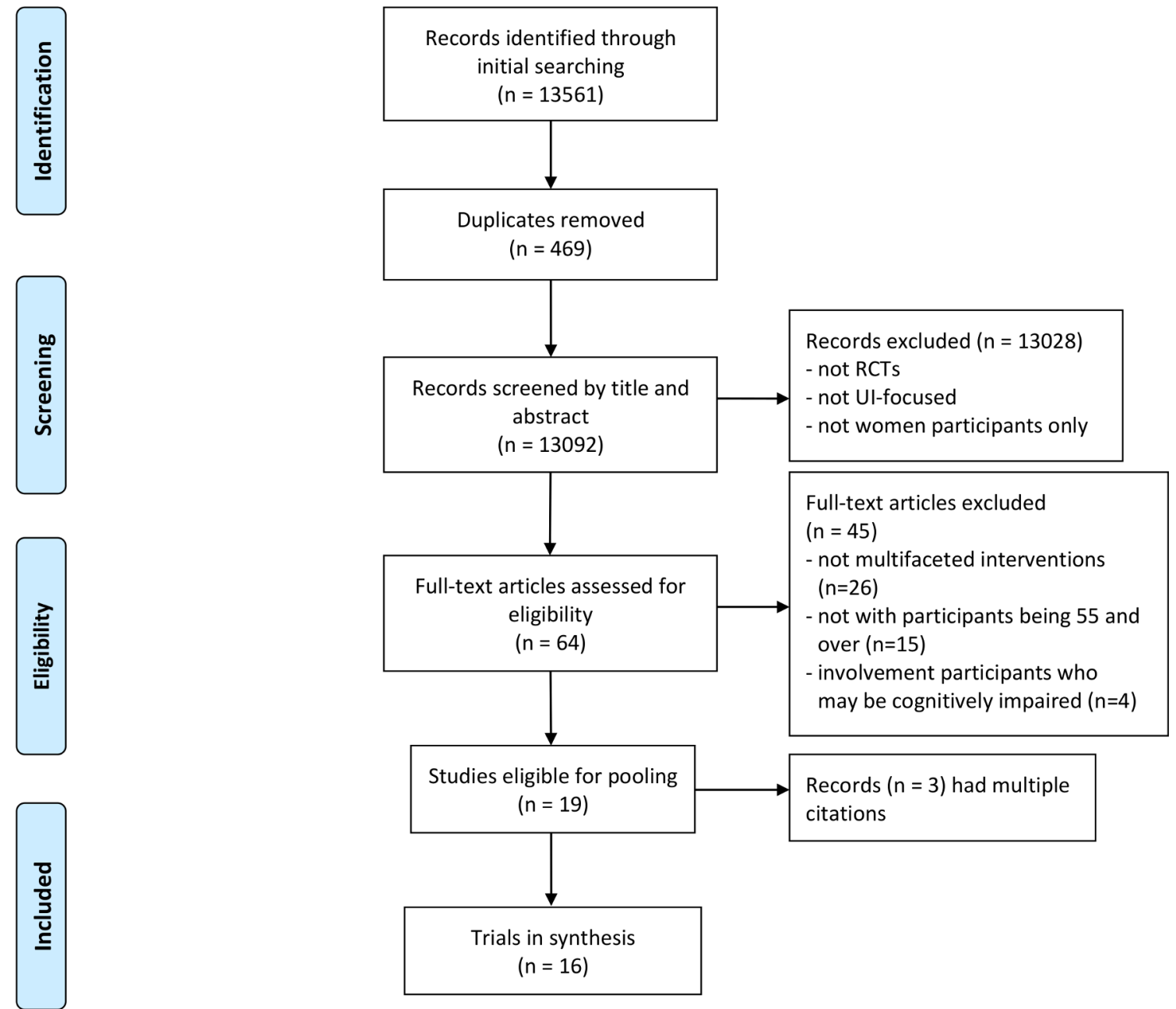

Figure 1 PRISMA flowchart. PRISMA, Preferred Reporting Items for Systematic Reviews and Meta-Analyses; RCT, randomised controlled trial; UI, urinary incontinence.

provision, PFME, bladder retraining, lifestyle modification and behavioural training that aimed to improve UI symptoms by changing peoples' behaviour and by teaching skills for preventing urine loss. A total of 11 studies $224962646568-7275$ had a conventional control treatment, including education, general lectures on health promotion, provision of general feedback, usual care, placebo and identical behavioural training without professional support or equipment, and five $\mathrm{e}^{666677374}$ designed a waiting list control group. Most interventions were delivered face to face; two were delivered in the format of internet based ${ }^{69}$ or via video conferencing. ${ }^{62}$ Length of the intervention varied from $60 \mathrm{~min}$ to 24 weeks with 12 weeks being the most common time period for intervention delivery $(n=5)$.

A variety of outcome measures were used, including urine leakage frequency (by self-reported diary, $n=14$ ) and volume (by pad weight test or measuring loss in $\mathrm{ml}, \mathrm{n}=5)$, pelvic floor muscle strength $(\mathrm{n}=3)$, psychological effect $(n=4)$, quality of life $(n=5)$, self-efficacy $(n=1)$ and perceived improvement $(n=10)$. Measures were regrouped into UI-specific items, physical functioning, emotional functioning, social functioning, pelvic floor muscle functioning, general health, self-management ability and subjective perceptions of change. However, not all measures used were reported by studies included, and the impact of UI on psychological health measured was identified as the most poorly reported domain, which was not reported by any studies. All except four studies ${ }^{6266} 7275$ defined their primary outcomes in the manuscript, but there was insufficient detail provided for study protocols to allow us to determine whether the reported primary outcome was that specified in the original study protocol. The characteristics of the included studies are presented in table 1.

\section{Interventions and associated outcomes}

Three broad types of multifaceted self-management interventions were identified: PFME-related interventions, bladder retraining related interventions and combination behavioural interventions.

A meta-analysis was not conducted due to the level of heterogeneity of intervention components, outcome measures, settings and participants. Effect size and 95\% CI were estimated for the primary outcome from each study based on information reported at the end of the 


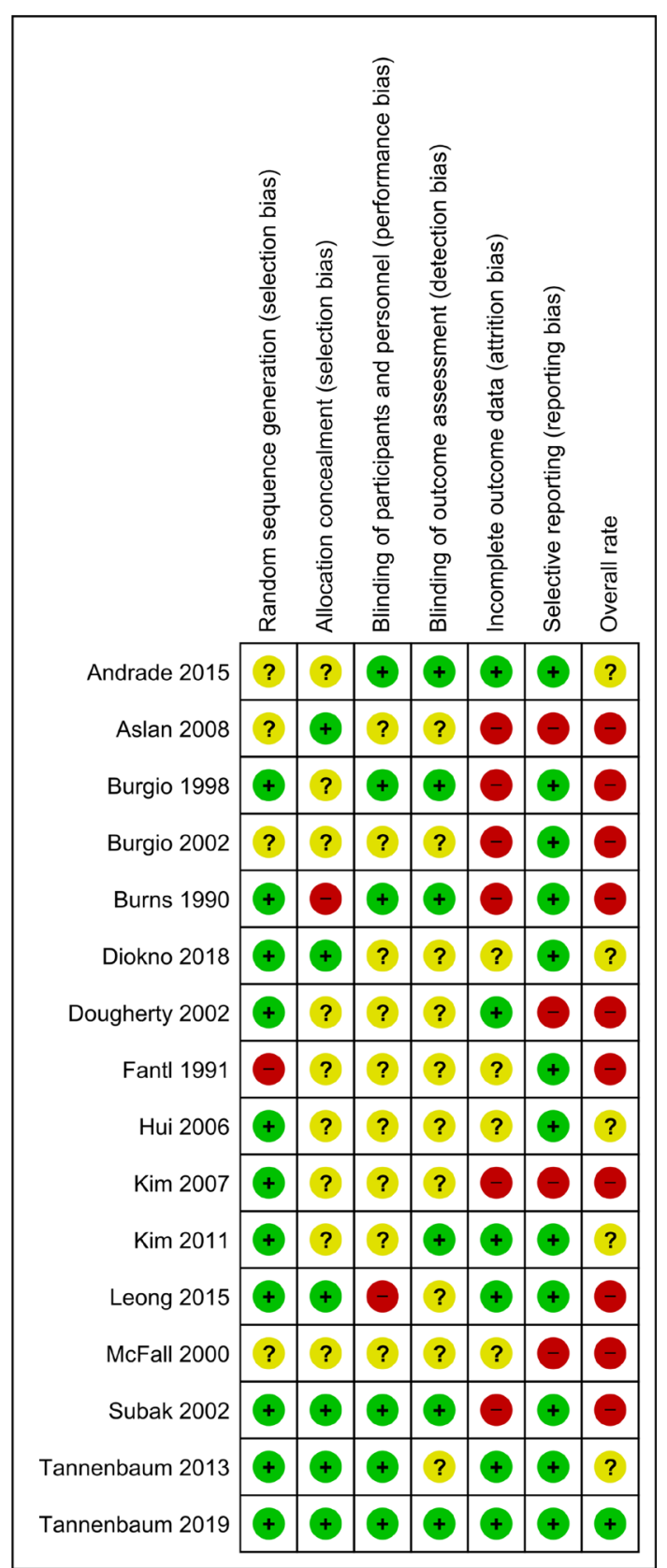

Figure 2 Risk of bias summary.

intervention. Where no primary outcome was defined, the outcome reflecting UI symptoms was estimated. The risk ratio (RR) was reported for dichotomous variables and the mean difference (MD) was reported for continuous variables (table 2).

Two studies reported no detailed description of the control intervention. ${ }^{66}{ }^{72}$ Four studies had not defined their primary outcomes ${ }^{62667275}$ but all of them observed a significant difference in UI symptoms in women in the intervention groups compared with the control groups. A total of 12 studies had the primary outcome clearly defined, and significant differences in UI symptoms were reported in the intervention groups compared with the control groups in 11 studies. These are described in more detail below.
PFME-related interventions

Three $^{636472}$ studies reported the effect of PFME as an element of a multifaceted intervention. PFME and general fitness exercises were delivered in two studies, ${ }^{6364}$ and PFME with biofeedback using a vaginal probe was delivered in one study. ${ }^{72}$ In these studies, PFME interventions were delivered as a group and participants were instructed in two formats: slow and quick contractions. Women were asked to contract the muscles and hold for seconds before relaxation in slow mode, whereas they were asked to tighten and relax as rapidly as they could in quick mode. Women were encouraged to practise both contractions together in different positions and record progress on a daily diary. Exercise frequency and duration reported varied. Women were instructed to perform up to $60 \mathrm{~min}$ general fitness exercise two times per week for 12 weeks $^{6364}$ and 20 min PFME four times a day for 8 weeks. $^{72}$

The first study ${ }^{63}$ reported a higher 'UI cure rate' in the PFME and fitness group versus general education and exercises ( $54.4 \%$ vs $9.4 \%$, RR 5.82, 95\% CI 1.90 to 17.86$)$. The second study ${ }^{64}$ reported a higher UI cure rate' in the PFME and fitness group versus general education classes (44.1\% vs $1.6 \%$, RR 26.88 , 95\% CI 3.77 to 191.79 ). The third study reported more women experiencing zero UI episodes in the PFME and biofeedback group than control (no description of the control intervention) (9 vs 1 , RR $8.55,95 \%$ CI 1.14 to 63.31$).^{72}$

Two studies evaluated the pelvic floor muscle by measuring adductor muscle in Newton-meters $(\mathrm{Nm}),{ }^{6364}$ and one study evaluated it by measuring quick contraction in microvolts and urethral closure pressure. ${ }^{72}$ The first study ${ }^{63}$ reported higher adductor muscle strength in the PFME and fitness group versus general education and exercises (59.4 vs 51.5, MD 7.90, 95\% CI 1.14 to 14.66 ). The second study ${ }^{64}$ reported a small increase in adductor muscle strength in the PFME and fitness group versus general education class (24.1 vs 22.1, MD 2.00 , 95\% CI -0.30 to 4.30 ). Women in the PFME and biofeedback group in the third study ${ }^{72}$ experienced stronger quick contractions than the control (5.96 vs 3.49, MD 2.47, $95 \%$ CI 0.38 to 4.56 ) but only a small increase in urethral closure pressure compared with the control (28.73 vs 28.06, MD $0.67,95 \% \mathrm{CI}-5.36$ to 6.70$)$.

\section{Bladder retraining related interventions}

One studies ${ }^{73}$ reported the effect of bladder retraining based interventions that compared with no treatment. ${ }^{73}$ Bladder retraining is designed to help the bladder become less overactive or sensitive, developed based on the principles of behaviour modification, aimed to alter one's desire to void and cut down the frequency of passing urine. ${ }^{73}$ Education was delivered together with bladder retraining interventions to support women to adapt the bladder retraining into their lifestyle. Women were instructed and encouraged to void at regularly scheduled intervals. Voiding intervals used varied ranging from 30 to $60 \mathrm{~min}$ based on their progress and tolerance, but the 


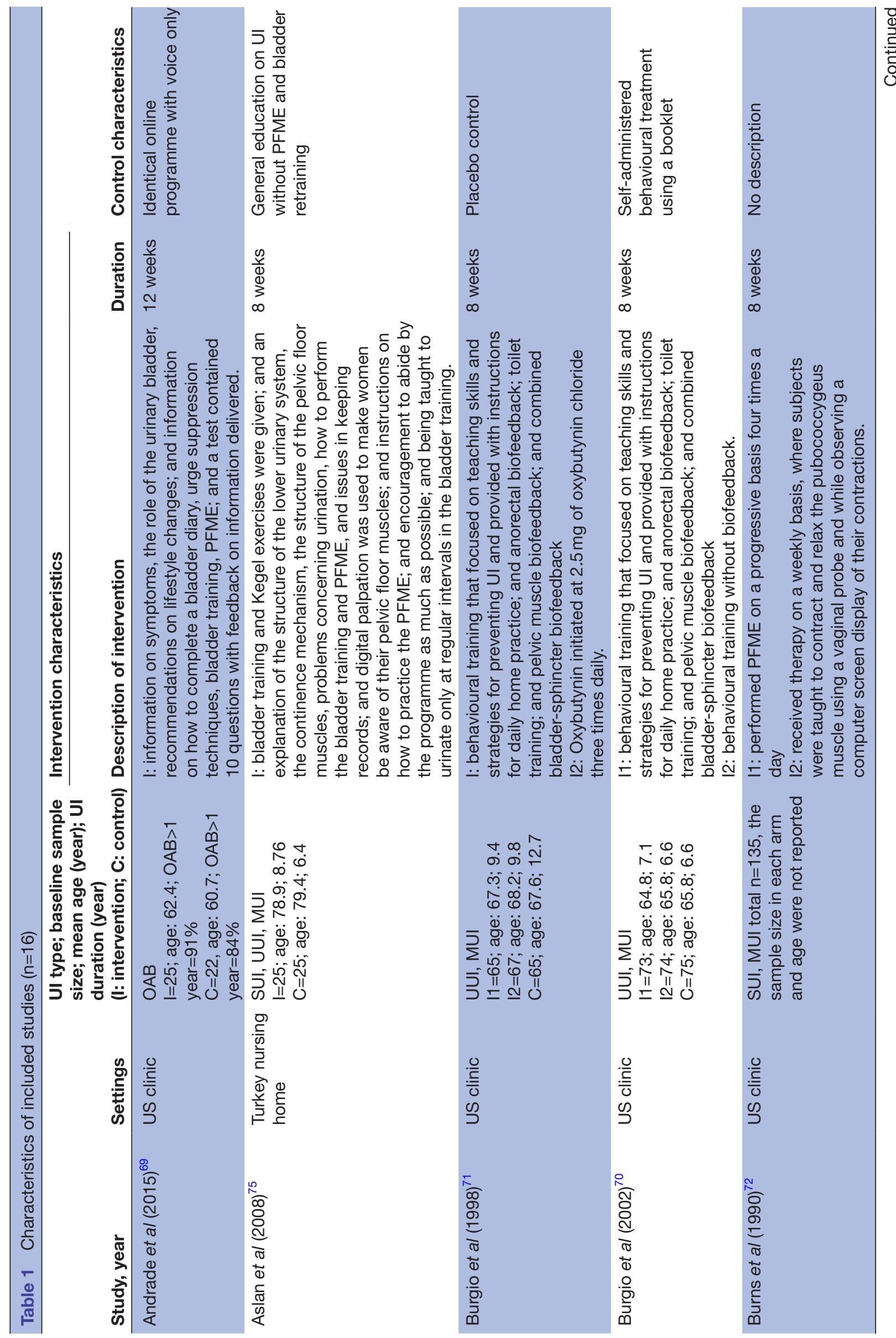




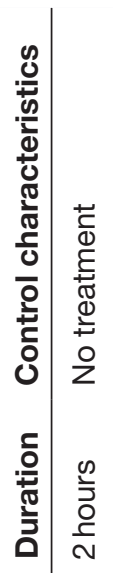

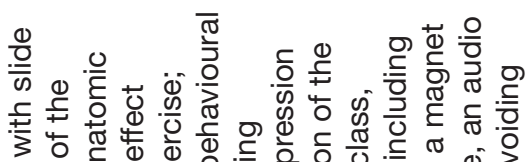
उ

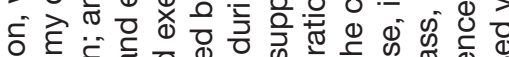

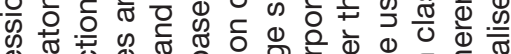

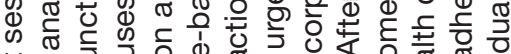

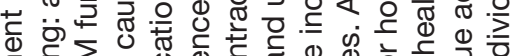

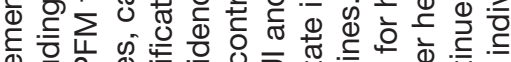
ه্

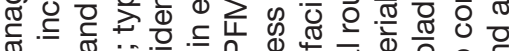

ธ。

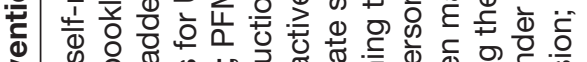

空

亲

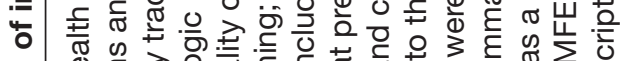

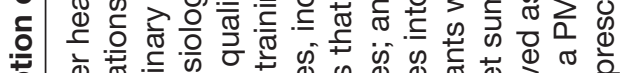

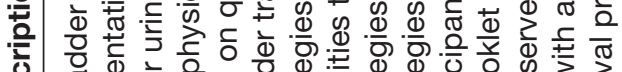

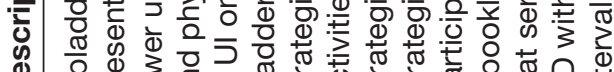

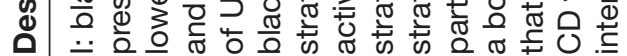

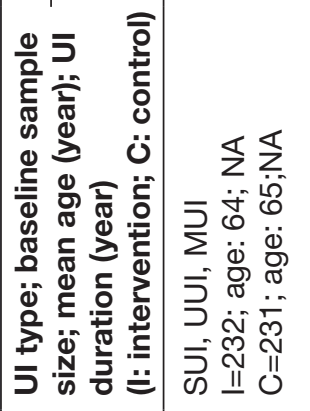

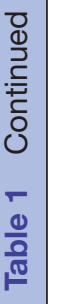

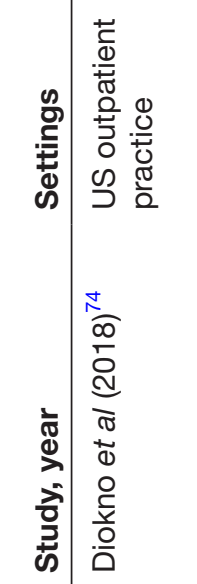

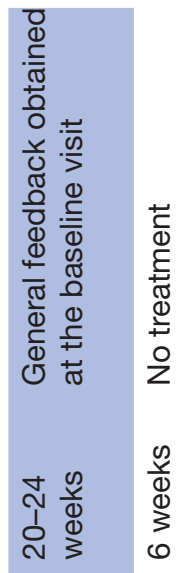
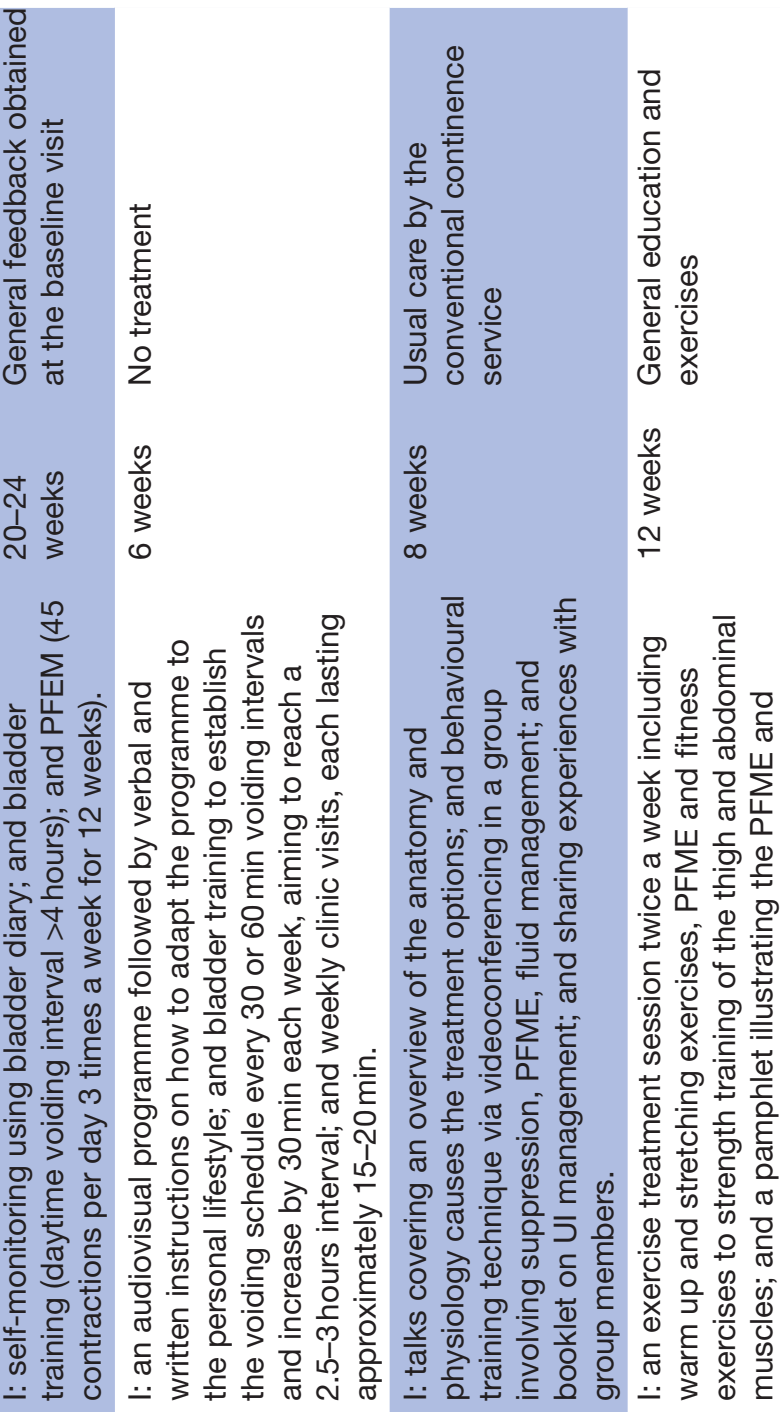

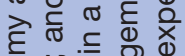

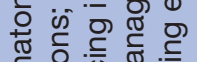

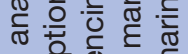

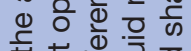

廿

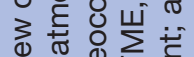

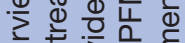

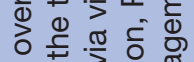

तै

צ 잉

ब ते ฮั

उ山ᄃ几

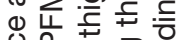

음

ऐक्य

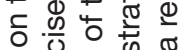

कू

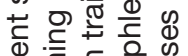

ह 등 등 은

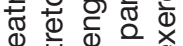

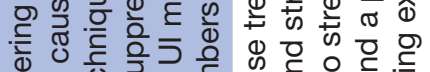

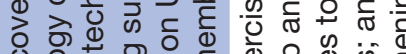

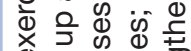

(1)

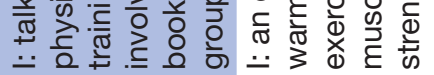
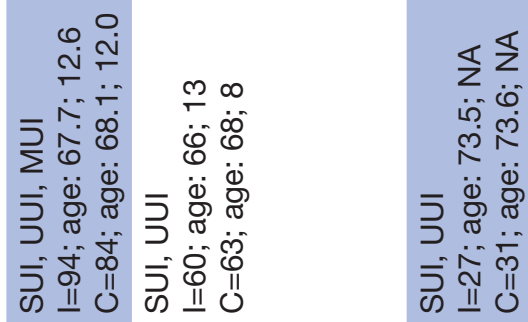

ำ

فํ்

ف

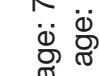

$=$ மें

क ला

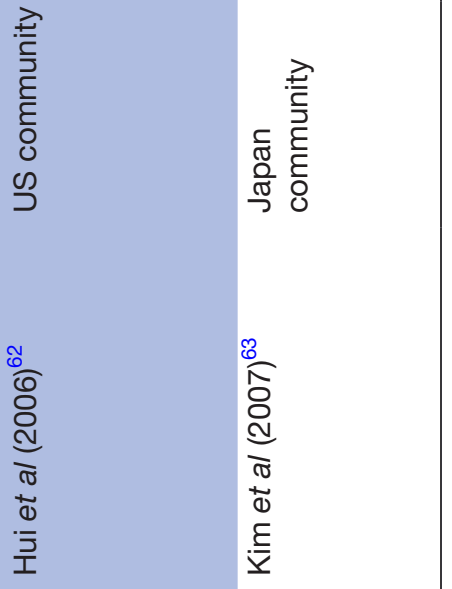




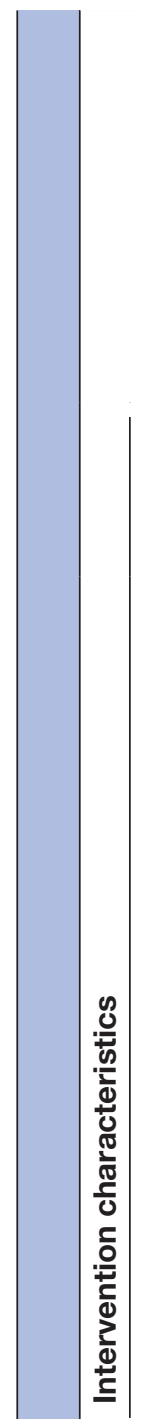

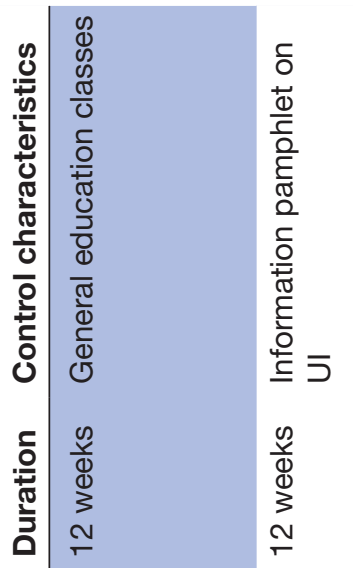

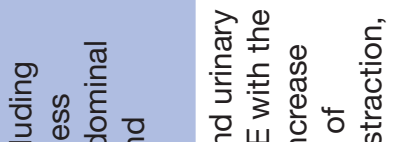

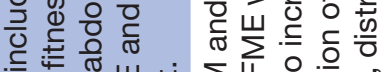

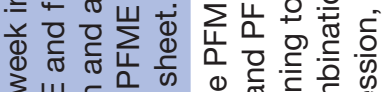
उ

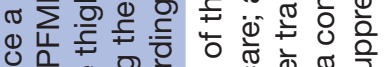
음

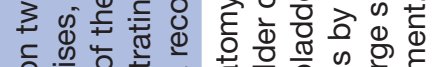

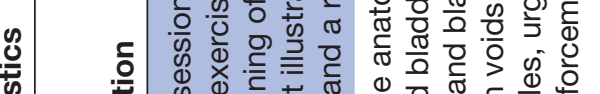

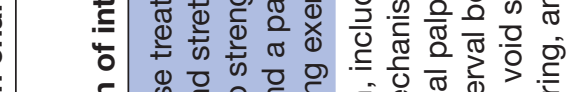

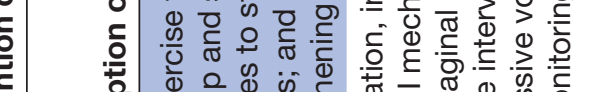

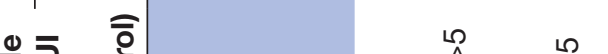

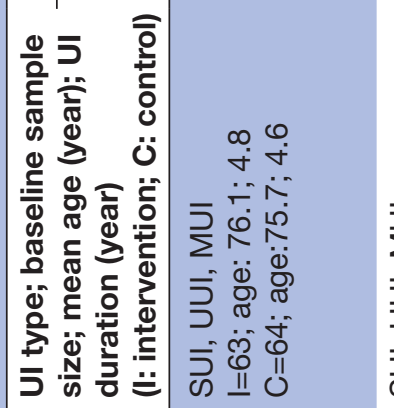

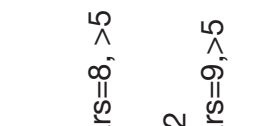

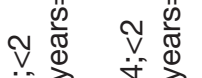

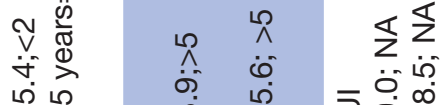

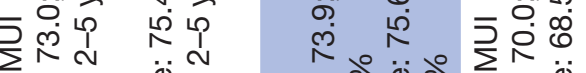

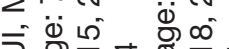

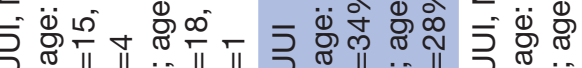

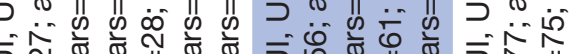

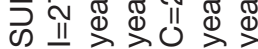
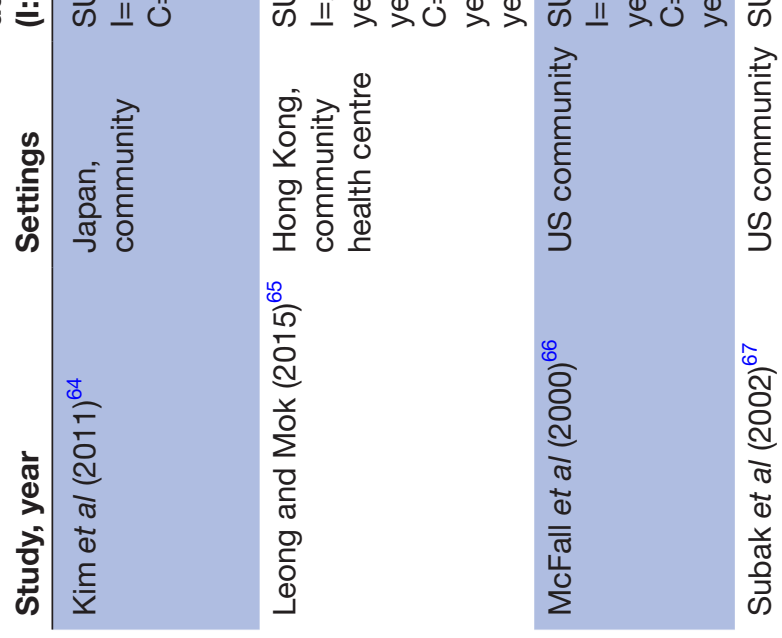

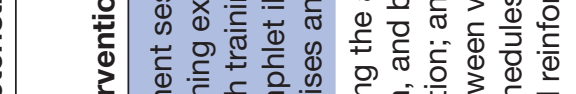

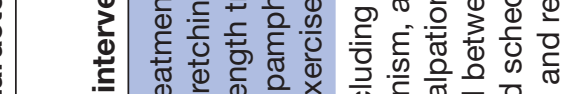

:츤

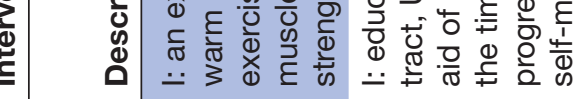
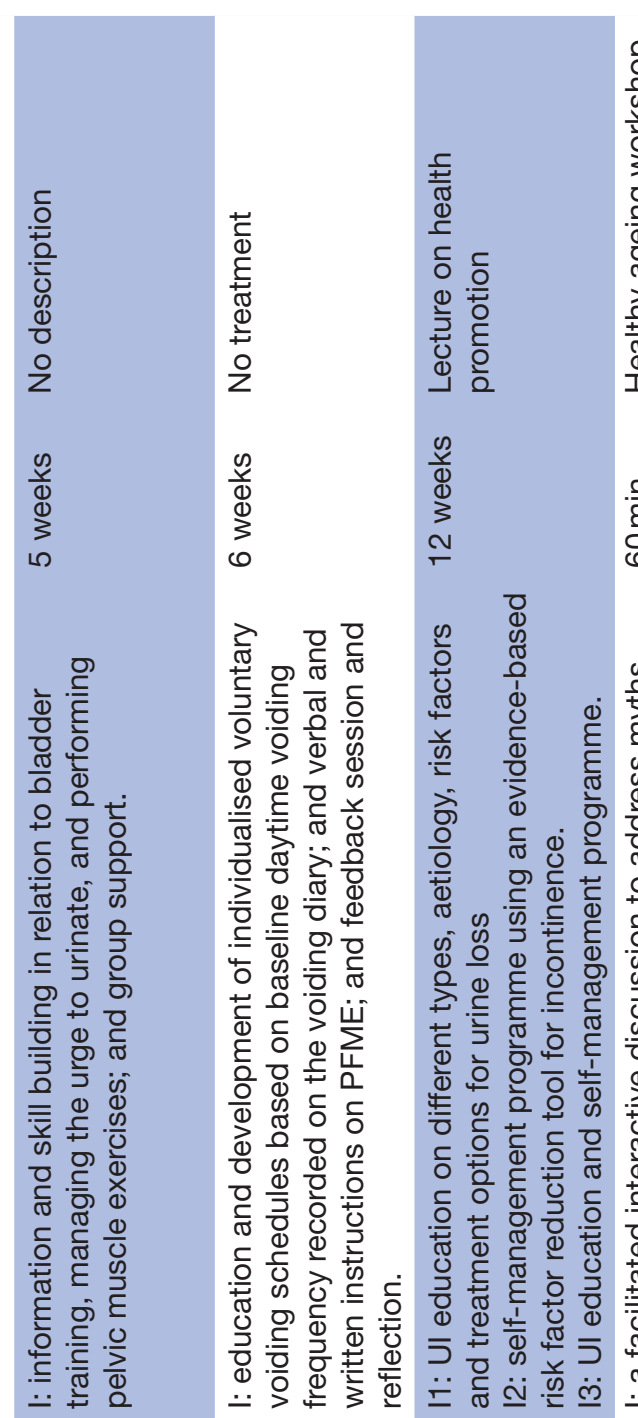

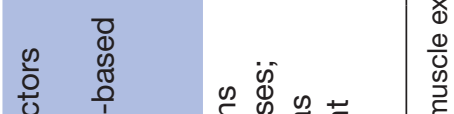

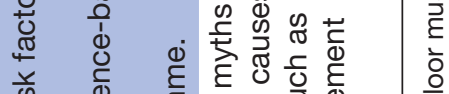

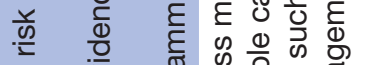

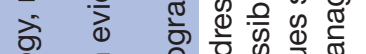

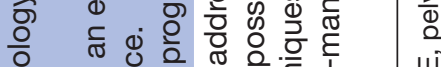

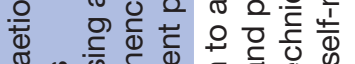
क क क के 골요

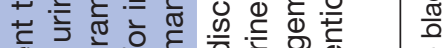
बे के 눙

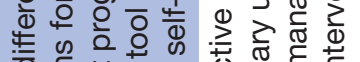

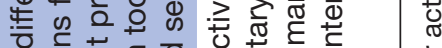

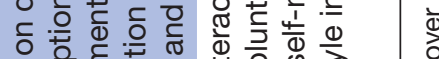

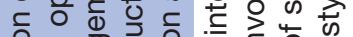
क

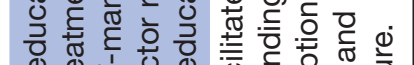

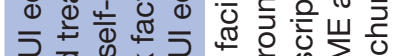

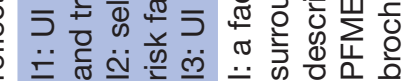

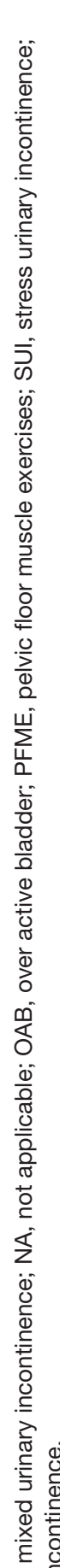

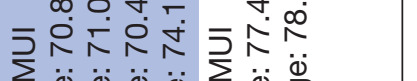

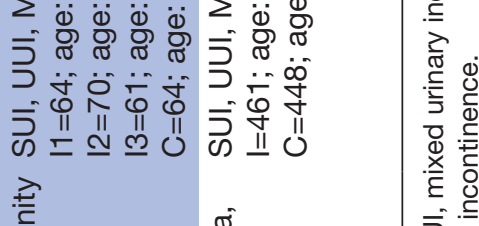




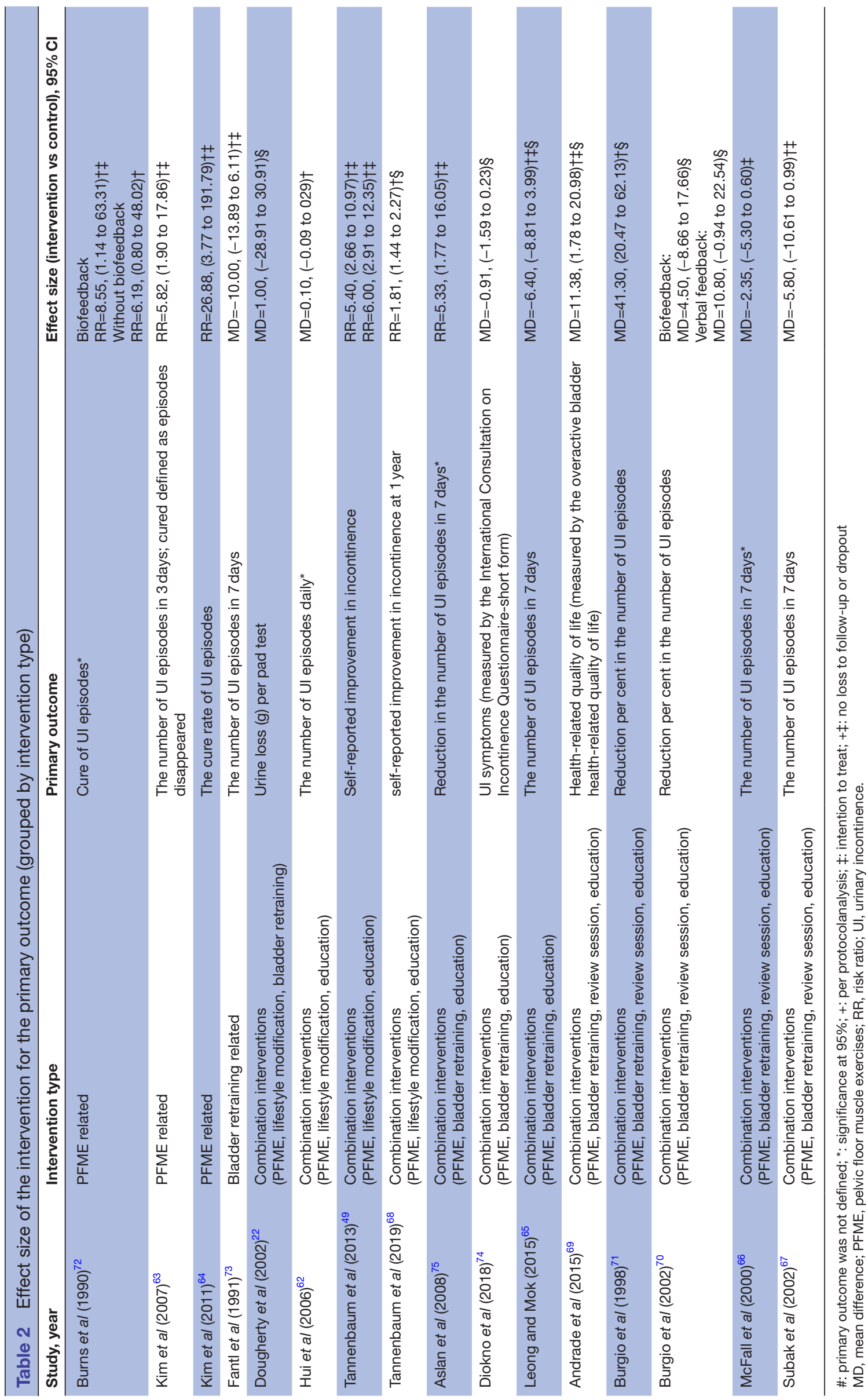


key was to suppress the urge as long as possible using relaxation and distraction techniques and not to void off the schedule.

This study reported a reduction in the number of UI episodes per week in the intervention group compared with the no treatment ${ }^{73}$ (MD $-10.00,95 \%$ CI -13.89 to -6.11 , or 1.4 fewer UI episodes per day). Women in the intervention group also experienced a reduction in urine loss (g) (MD -30.00, (95\% CI -53.33 to -6.67).

\section{Combination behavioural interventions}

\section{Interventions comprising PFME, lifestyle modification and bladder} retraining

One study ${ }^{22}$ reported the effect of behavioural training intervention comprising PFME, lifestyle modification and bladder retraining compared with general feedback. Women in the intervention group were supported to self-monitor their caffeine consumption, the amount and timing of fluid intake, voiding intervals, dietary and bowel function, to practise bladder retraining, and to perform PFME with biofeedback. Interventions lasted 20-24 weeks facilitated by a nurse.

Although urine loss measured on a pad (gram/24hours) was not significantly different from a control group that received feedback alone (MD $1.00 \mathrm{~g} / 24$ hours, $95 \% \mathrm{CI}-28.91$ to 30.91 ), the number of UI episodes did differ with the intervention group experiencing 0.8 fewer episodes per day compared with the control group (MD $-0.80,95 \%$ CI -1.42 to -0.18 ). Self-reported quality of life was lower (lower scores reflecting higher quality of life) (MD $-5.80,95 \%$ CI -9.81 to -1.79 ) and subjective assessment of UI severity (higher scores reflecting less UI severity) (MD 1.22, 95\% CI 0.89 to 1.55 ) were better for the intervention compared with the control.

\section{Interventions comprising PFME, lifestyle modification and} education

Three studies ${ }^{49} 6268$ reported the effect of a behavioural training intervention comprising PFME, lifestyle modification and education. Tannenbaum et al ${ }^{49}$ performed a cluster randomised trial lasting 12 weeks, where the intervention delivered to $8-16$ participants by a single facilitator was compared with a group lecture on health promotion. Hui et a $t^{62}$ compared a telemedicine continence programme with conventional outpatient UI service. Women in the intervention group attended a videoconference class where they received information on anatomy and physiology of the urinary system, causes of UI, treatment options, behavioural management techniques including PFME, fluid management and dietary. Interventions lasted 8 weeks and the videoconference class was facilitated by the nurse specialist and a researcher for the behavioural training. The other study by Tannenbaum et $a l^{68}$ compared an in-person $60 \mathrm{~min}$ UI self-management workshop with a control healthy ageing workshop involving older women recruited from multicommunities in the UK, Canada and France.
In Tannenbaum et al, ${ }^{49}$ more women in the intervention group reported improvement in UI symptoms than the control group (RR 5.40, (95\% CI 2.66 to 10.97). Compared with controls, the participants in the combined intervention reported an adjusted mean 2.05 points (95\% CI 0.87 to 3.24) greater improvement on the International Consultation on Incontinence Questionnaire (ICIQ) from baseline to 3-month follow-up. In Hui et al, ${ }^{62}$ no primary outcome was defined. There was only a small reduction observed in both intervention and control groups for the number of UI daily episodes ( 0.20 vs 0.10 , MD $0.10,95 \%$ CI -0.09 to 029 ), and for the frequency of daily voiding ( 8.50 vs 9.00 , MD $-0.50,95 \%$ CI -1.92 to 0.92$)$. However, there was a greater reduction in the volume of urine loss $(\mathrm{mL})$ at each micturition in the intervention compared with the control group (MD $39.00,95 \%$ CI 19.21 to 58.79). In the second study by Tannenbaum et $a l^{68}$ the primary outcome was self-reported UI improvement at 1 year. There were $15 \%$ of the intervention group versus $6.9 \%$ of controls reported significant improvements in UI (RR 2.16, 95\% CI 1.45 to 3.24 ), and $35 \%$ vs $19 \%$ reported any improvement (RR $1.81,95 \%$ CI 1.44 to 2.27). Compared with controls, women in the intervention group also reported a mean 1.3 point greater improvement on the quality of life score at 1 year (95\% CI 1.2 to 1.4 ).

\section{Interventions comprising PFME, bladder retraining and education} Three studies ${ }^{65} 7475$ reported the effect of a behavioural training intervention comprising PFME, bladder retraining and education. These behavioural training based interventions were compared with an information pamphlet on UI ${ }^{65}$ no treatment ${ }^{74}$ and general education on UI without PFME and bladder retraining ${ }^{75}$ respectively. Women in the intervention groups received information on structure and mechanism of the lower urinary system and UI, the structure of the pelvic floor muscles, together with bladder retraining and PFME techniques. Interventions lasted varied ranging from 2 hours to 12 weeks and were facilitated by an a physiotherapist, ${ }^{65}$ a trained health professional ${ }^{74}$ or a urogynaecology nurse. ${ }^{75}$

Leong and $\mathrm{Mok}^{65}$ observed a lower frequency of UI episodes (over 1 week) in the intervention group compared with the control (MD $-6.40,95 \%$ CI -8.81 to -3.99 ). An improvement was also observed in self-reported quality of life (measured by the Incontinence Impact Questionnaire Short Form with lower scores reflecting higher quality of life) (MD $-3.90,95 \%$ CI -5.03 to -2.77 ) and perception of improvement reported at the end of trial by the patient (measured by a $10 \mathrm{~cm}$ Visual Analogue Scale) (MD 7.30, 95\% CI 6.84 to 7.76). Diokno et al ${ }^{74}$ reported that the intervention group had lower estimates of UI symptoms (MD $-0.91,95 \%$ CI -1.59 to -0.23 ), and that a higher proportion of intervention group patients rated themselves as 'much/very much better' (RR 5.82, 95\% CI 3.61 to 9.39) compared with the control. Women in the intervention group also reported significantly higher scores on quality of life measured by the Incontinence 
Quality of Life Questionnaire (MD 5.11, 95\% CI 2.37 to 7.85) compared with the control group. The number of daily voids (MD $-1.26,95 \%$ CI -1.62 to -0.90$)$ and UI episodes per day (MD $-0.45,95 \% \mathrm{CI}-0.67$ to -0.23 ) were significantly lower for the intervention group than for the control group when estimated using a 3-day void diary. The urine volume loss $(\mathrm{g})$ in 24 hours (MD $-4.53,95 \%$ CI -6.34 to -2.72 ) was lower in the intervention than the control group. The Medical, Epidemiologic and Social Aspects of Ageing urge (MD -5.53, 95\% CI -9.34 to -1.36 ) and stress UI (MD $-6.25,95 \%$ CI -10.75 to -1.75 ) scores were significantly lower for the intervention group than for the control group, but there were no differences between the groups on the pelvic floor muscle strength (RR $0.96,95 \%$ CI 0.80 to 1.15 ). No primary outcome was defined in Aslan $e t a l,{ }^{75}$ but there were fewer complaints of frequency (RR 5.33, 95\% CI 1.77 to 16.05 ), nocturia (RR 17.00, 95\% CI 1.03 to 279.53) and urgency (RR 3.25, $95 \%$ CI 1.23 to 8.61 ) in the intervention group compared with the control.

\section{Interventions comprising PFME, bladder retraining, education and} feedback

Five studies ${ }^{66} 6769-71$ reported the effect of a behavioural training intervention comprising PFME, bladder retraining, education and feedback compared with a control group with no description, ${ }^{66}$ no treatment, ${ }^{67}$ online audio programme ${ }^{69}$ stand-alone self-management booklet ${ }^{70}$ and placebo. ${ }^{71}$ Interventions studied included information on the condition, instructions on completing a bladder diary, skills and strategies needed for PFME and bladder retraining, and feedback session and reflection used for reviewing progress, setting new goals and encouraging persistence. PFME with biofeedback was delivered to women in two studies, ${ }^{70} 71$ and in one study PFME with biofeedback was compared against PFME with verbal feedback and against control. ${ }^{70}$ Interventions lasted from 5 to 12 weeks. Two studies ${ }^{70}{ }^{71}$ delivered interventions face to face, two were in small groups facilitated by trained instructors ${ }^{66}$ and nurse educators, ${ }^{67}$ and one provided an online education programme using a generic avatar coach. ${ }^{69}$

No primary outcome was defined in McFall et al. ${ }^{66}$ There was a small reduction in the intervention in the number of UI episodes (MD -2.35, 95\% CI -5.30 to 0.60), and a slight increase frequency of nocturnal urine loss per week (MD 0.30, 95\% CI -2.70 to 3.30) compared with the control group. However, women in the intervention group experienced a lower frequency of diurnal micturition per week (MD $-12.33,95 \% \mathrm{CI}-18.87$ to -5.79 ) than the control group.

In Subak et al, ${ }^{67}$ women in the intervention group experienced fewer 'total UI episodes per week' (MD -5.80 , 95\% CI -10.61 to -0.99 ), fewer 'diurnal UI episodes per week' (MD $-5.40,95 \%$ CI -9.76 to -1.04 ) and less 'diurnal micturitions per week' (MD $-8.70,95 \%$ CI -15.24 to 2.16 ) compared with the control group. There was only a small reduction in the intervention in the number of nocturnal
UI episodes per week (MD -0.30, 95\% CI -1.11 to 0.51 ) or in total micturitions per week (MD $-6.00,95 \%$ CI -13.91 to 1.09) compared with the control.

In Andrade et $a l,{ }^{69}$ women reported higher scores in their quality of life (measured by the Overactive bladder Health-related Quality of Life) (MD 11.38, 95\% CI 1.78 to 20.98 ), less daily frequency (MD -3.31 , (95\% CI -4.26 to 2.36 ), less daily urgency (MD $-2.14,95 \% \mathrm{CI}-2.92$ to -1.36 and less daily urge UI episodes (MD $-2.12,95 \%$ CI -3.13 to -1.1$)$ in the intervention group compared with the control group. There was a significantly lower caffeine intake per 24 hours (Fl. Oz.) (MD -2.21, 95\% CI -4.23 to -0.18 ) in the intervention group compared with the control group. No differences were observed in urge self-efficacy (measured by the Geriatric Self-efficacy Index for UI with higher scores reflecting a higher level of efficacy) (MD 0.86, 95\% CI -0.21 to 1.95 ) or PFME self-efficacy (measured by a Visual Analogue Scale with higher scores reflecting higher level of efficacy) (MD $0.004,95 \% \mathrm{CI}-1.57$ to 1.57 ). There were no differences between groups on the measure of perception of bladder condition (MD $0.22,95 \%$ CI -0.60 to 1.04).

In Burgio et $a l^{70}$ interventions with biofeedback resulted in a mean $63.1 \%$ reduction in the frequency of UI episodes (MD 4.50, 95\% CI -8.66 to 17.66) and $69.4 \%$ reduction in interventions with verbal feedback (MD $10.80,95 \%$ CI -0.94 to 22.54 ). However, these were not significantly differences compared with the control. Women in the biofeedback group reported having 'fewer accidents' than control group participants (RR 1.12, (95\% CI 1.02 to 1.22), 'smaller accidents' (RR 1.33, (95\% CI 1.08 to 1.64), and were 'able to wear less protection' (RR 1.34, 95\% CI 1.01 to 1.79 ). A higher proportion of women in the verbal feedback group, compared with the control group, described that they felt they had better progress (RR 1.14, (95\% CI 1.03 to 1.26). No difference was observed across groups in terms of women being satisfied with treatment progress (biofeedback vs control: RR $1.03,95 \%$ CI 0.96 to 1.10 ; verbal feedback vs control: RR $1.05,95 \%$ CI 0.98 to 1.12 ).

In Burgio et $a l^{71}$ there was a large reduction in the number of UI episodes (reported as per cent reduction) in the intervention group versus the control group (MD $41.30,95 \%$ CI 20.47 to 62.13 ). Compared with the control, women in the intervention group experienced 'fewer accidents' (RR 1.52, 95\% CI 1.25 to 1.86 ) and fewer had 'smaller accidents' (RR 1.62, 95\% CI 1.23 to 2.13). Unsurprisingly, therefore, more women in the intervention group felt 'able to wear less protection' (RR 1.76, 95\% CI 1.24 to 2.50). A higher proportion of women in the intervention group than the control group reported that the frequency of UI had completely reduced (RR 2.34, 95\% CI 1.11 to 4.94 ) and were satisfied with treatment progress (RR $1.52,95 \%$ CI 1.25 to 1.86). 


\section{DISCUSSION}

This review synthesised the outcomes from 16 RCTs that evaluated the multifaceted self-management interventions for women with UI aged 55 or over. Three types of multifaceted interventions that included PFME related, bladder retraining related and combination behavioural interventions were developed. These multifaceted interventions are potentially useful approaches to the UI management, however, there was insufficient evidence to determine whether any of the combination of components is superior to others in improving UI symptoms.

Most of the studies included were of poor or unclear quality, although a statistically significant difference in UI symptoms was reported across all three types of multifaceted self-management interventions. In addition, no information in studies of poor or unclear quality reported on whether these outcome differences were also clinically significant. With only limited work undertaken determining the clinically relevant reference points for certain UI outcome measures, ${ }^{76}$ future research is needed to clarify the meaning of clinical significance. Given the lack of core outcomes for use in this area, the absence of trial registration, and the very wide range of outcomes reported, it is highly likely that there is selective reporting of outcomes, which is commonly related to the size and direction of effect sizes. ${ }^{77}$

Interventions were categorised into three types to reflect the key components, however, the effects of those key components were not always evidenced by measures chosen or outcomes reported. For instance, although PFME-related interventions improved women's urine leakage, the strength of pelvic floor muscle was not simultaneously significantly changed. This may be related to study power or the fact that some women were unable to perform correctly or adhere to the PFME, or there was a lack of follow-up support. PFME is recommended as a first-line treatment for good clinical practice, ${ }^{9}$ however, research suggested that many women cannot initially contract their muscles correctly if they are only provided with a simple verbal instruction. ${ }^{78}$ Improvement may be achieved by providing more detailed education on contraction technique and frequent appointments during the training programme. ${ }^{79}{ }^{80}$ Similarly, the number of UI episodes was significantly lower for the intervention group in the study using bladder retraining related interventions. Unfortunately, there were no outcome measures chosen relating to voiding intervals. ${ }^{73}$ No conclusion can be drawn in terms of the most effective combination of components in practice. These identified components are often referred to as a group of behavioural treatments, which need to be tailored to the individual needs and the characteristics of the symptoms.

Unlike other chronic conditions such as chronic pain, ${ }^{81}$ there is a lack of core outcome sets developed for women with UI. Leading organisations, for example, the ICIQ and the US Food and Drug Administration recommended patient-centred outcomes to be included in trials $^{82} 83$ for women with UI. However, the fact that no standard core outcome sets are available raises concern for outcome selection bias, which also makes it difficult to undertake a meaningful comparison between trials. While much attention has been paid to standardising the methods and procedures, the collection and reporting of outcomes have been neglected in RCTs in the area of UI. ${ }^{84}$ Without supporting evidence, a range of outcomes measures used in clinical trials may also be burdensome to participants, researchers and health professionals. ${ }^{85}$ It is also possible to have conflicting results reported when many measures are used without clear rationale. ${ }^{86}$ Future research is needed to develop core outcome sets with recommended measures to be used in trials investigating interventions for women with UI.

In estimating the effectiveness of multifaceted self-management interventions of UI, it would also be helpful to have the information on adherence. In these studies, unfortunately, adherence to self-management components was inconsistently monitored or reported. Continued adherence might be important to maintain the effectiveness of treatment and therefore to improve quality of life, but it is estimated that less than two-thirds of patients $(64 \%)$ adhere to PFME and other advice during the treatment period when being supervised, and less than one-third $(23 \%)$ remain adherent without supervision. ${ }^{87}$ Evidence suggests positive adherence intentions, self-efficacy, attitudes towards and perceived benefits of treatment, and social pressure may impact adherence and might be amenable to health professional intervention, for example, by setting personalised self-management goals and adopting patient-centred adherence strategies. ${ }^{88} 89$ More evidence is needed to develop and further test adherence strategies as an added intervention to self-management.

Self-reported improvement in UI severity increased significantly compared with the control in some studies using behavioural training interventions. Patients' subjective evaluation of outcomes including satisfaction with treatment progress has been recognised as an important aspect of healthcare outcomes and a quality indicator for many health services. ${ }^{90}$ Patients' modified behaviours and lifestyles have also been found to be associated with self-management ability in people living with chronic conditions. $^{37}$ Self-management ability is an important indicator to be assessed, and it reflects the extent to which participants engage with the interventions and develop skills to control their symptoms. Rather than solely focusing on clinical indicators such as wet episodes or volume of leakage, subjective ratings can provide empirical evidence on the effectiveness, feasibility and acceptability of the intervention. ${ }^{91} 92$

The majority of the included studies were conducted in local communities where women were identified and recruited. This may reflect the reluctance of women to present with the condition or the fact that little attention has been given by health professionals, ${ }^{93}$ although the guideline by National Institute for Health and Care Excellence recommends that all women should be asked 
about bladder and bowel health. ${ }^{9}$ It is a particular issue for older people who frequently visit health professionals but do not actively seek medical help for their UI. Given the fact that care pathways for older women with UI can be complex involving consultants, urologist or urogynaecologist, physiotherapists and nurses, identifying those with higher risks and providing timely medical care and support at early stages would be of benefit in primary care settings.

\section{Implications}

Given the fact that most of the studies were of poor or unclear quality, there is a need for high-quality studies with a rigorous design and high methodological quality to evaluate the effectiveness of multifaceted interventions, and subsequently the comparative effectiveness. Most of the included studies were conducted in local communities, future studies are also needed to explore whether self-management interventions can improve outcomes for patients in clinical settings. To establish solid conclusions for all the other comparisons, there is a need to develop core outcome sets and to identify the clinically relevant reference points for women with UI. Although this review suggested the potential associations between these self-management interventions and identified outcomes, the optimal components of effective interventions and their mechanism remain unclear. $^{94}$ More research is needed to identify the active components and determine the effect size of self-management for UI management.

This review found that the group of multifaceted behavioural techniques, including PFME, bladder retraining and combination interventions, are potentially useful approaches to the UI management. The findings of this review also highlight the tailored support for individuals with an aim to improve their physical, psychological and social functioning may be useful to be implemented in multidisciplinary continence services in primary care. Our confidence in these findings is low as the RCTs most were at high or unclear risk of bias. Also, it would be useful to understand patients' satisfaction on treatment received for UI management in practice.

\section{Limitations}

There were potential weaknesses in this review. It was limited by the fact that only studies published in English were included. No study was considered of high quality. Publication bias may exist, as the majority of studies published reporting significant results. ${ }^{95}$ Given that most of the multifaceted interventions were delivered by providers who were either researchers or health professionals, theoretical bias arising from therapeutic alliance related to the quality of provider-participant relationship may exist which may lead to the placebo effect. Due to analysis in the included studies being conducted with mixed samples, subgroup analysis was impossible to be carried out in this review in order to examine whether effects of interventions differ across subgroups according to the type of UI.

\section{Conclusion}

This review found that PFME, bladder retraining and combination behavioural based, multifaceted interventions are potentially useful approaches to the UI management. There was insufficient evidence to determine whether any of the combination of components is superior to others in improving UI symptoms. It is likely that behavioural interventions comprising multiple components targeting symptom management, emotional and social functioning would be candidates for the future development of tailored self-management interventions.

Acknowledgements We thank women and health professionals' involvement and their input on the study design.

Contributors YF: study design, data collection and analysis, drafting and revising the manuscript. EAN: supervision of study design, data collection and analysis, revising the manuscript. LM: supervision of study design, data collection and analysis, revising the manuscript.

Funding This work was supported by Leeds Benevolent Society for Single Ladies, a Charitable Incorporated Organisation (registered charity number 1155794).

Competing interests None declared.

Patient consent for publication Not required.

Provenance and peer review Not commissioned; externally peer reviewed.

Data availability statement All data relevant to the study are included in the article or uploaded as online supplementary information.

Open access This is an open access article distributed in accordance with the Creative Commons Attribution Non Commercial (CC BY-NC 4.0) license, which permits others to distribute, remix, adapt, build upon this work non-commercially, and license their derivative works on different terms, provided the original work is properly cited, appropriate credit is given, any changes made indicated, and the use is non-commercial. See: http://creativecommons.org/licenses/by-nc/4.0/.

\section{REFERENCES}

1. Abrams P, Cardozo L, Fall M, et al. The standardisation of terminology of lower urinary tract function: report from the standardisation Sub-committee of the International continence Society. Am J Obstet Gynecol 2002;187:116-26.

2. NHS England. Excellence in continence care: practical guidance for commissioners, and leaders in health and social care Leeds: NHS England,, 2018. Available: https://www.england.nhs.uk/wp-content/ uploads/2018/07/excellence-in-continence-care.pdf [Accessed 18th Oct 2018].

3. Al-Mukhtar Othman J, Åkervall S, Milsom I, et al. Urinary incontinence in nulliparous women aged 25-64 years: a national survey. Am J Obstet Gynecol 2017;216:149.e1-11.

4. Thom D. Variation in estimates of urinary incontinence prevalence in the community: effects of differences in definition, population characteristics, and study type. J Am Geriatr Soc 1998;46:473-80.

5. Erekson EA, Cong X, Townsend MK, et al. Ten-Year prevalence and incidence of urinary incontinence in older women: a longitudinal analysis of the health and retirement study. J Am Geriatr Soc 2016;64:1274-80.

6. Hunskaar S, Lose G, Sykes D, et al. The prevalence of urinary incontinence in women in four European countries. BJU Int 2004;93:324-30.

7. Hunskaar S, Arnold EP, Burgio K, et al. Epidemiology and natural history of urinary incontinence. Int Urogynecol J Pelvic Floor Dysfunct 2000;11:301-19.

8. Nitti VW. The prevalence of urinary incontinence. Rev Urol 2001;3(Suppl 1):S2.

9. NICE. Urinary incontinence and pelvic organ prolapse in women: management: National Institute for Health and Care Excellence, 2019. Available: https://www.nice.org.uk/guidance/ng123/resources/ urinary-incontinence-and-pelvic-organ-prolapse-in-womenmanagement-pdf-66141657205189 [Accessed 14th Jun 2019].

10. Turner DA, Shaw C, McGrother CW, et al. The cost of clinically significant urinary storage symptoms for community dwelling adults in the UK. BJU Int 2004;93:1246-52. 
11. Garcia JA, Crocker J, Wyman JF, et al. Breaking the cycle of stigmatization: managing the stigma of incontinence in social interactions. J Wound Ostomy Continence Nurs 2005;32:38-52.

12. Elstad EA, Taubenberger SP, Botelho EM, et al. Beyond incontinence: the stigma of other urinary symptoms. J Adv Nurs 2010;66:2460-70.

13. Shaw C. A review of the psychosocial predictors of help-seeking behaviour and impact on quality of life in people with urinary incontinence. J Clin Nurs 2001;10:15-24.

14. O'Donnell M, Lose G, Sykes D, et al. Help-seeking behaviour and associated factors among women with urinary incontinence in France, Germany, Spain and the United Kingdom. Eur Urol 2005:47:385-92.

15. Lukacz ES, Santiago-Lastra Y, Albo ME, et al. Urinary incontinence in women: a review. JAMA 2017;318:1592-604.

16. Koch T, Kralik D, Eastwood S, et al. Breaking the silence: women living with multiple sclerosis and urinary incontinence. Int J Nurs Pract 2001;7:16-23.

17. Hägglund $D$, Wadensten $B$. Fear of humiliation inhibits women's care-seeking behaviour for long-term urinary incontinence. Scand $J$ Caring Sci 2007;21:305-12.

18. Buckley BS, Lapitan MCM. Prevalence of urinary incontinence in men, women, and children-current evidence: findings of the fourth International consultation on incontinence. Urology 2010;76:265-70.

19. Dugan E, Roberts CP, Cohen SJ, et al. Why older CommunityDwelling adults do not discuss urinary incontinence with their primary care physicians. J Am Geriatr Soc 2001;49:462-5.

20. Horrocks $\mathrm{S}$, Somerset $\mathrm{M}$, Stoddart $\mathrm{H}$, et al. What prevents older people from seeking treatment for urinary incontinence? A qualitative exploration of barriers to the use of community continence services. Fam Pract 2004;21:689-96.

21. Eustice S, Roe B, Paterson J, et al. Prompted voiding for the management of urinary incontinence in adults. Cochrane Database Syst Rev 2000;29.

22. Dougherty MC, Dwyer JW, Pendergast JF, et al. A randomized trial of behavioral management for continence with older rural women. Res Nurs Health 2002;25:3-13

23. Stewart F, Berghmans B, Bø K, et al. Electrical stimulation with non-implanted devices for stress urinary incontinence in women. Cochrane Database Syst Rev 2017;153(4 Suppl).

24. Hay-Smith EJ, Bø Berghmans LC, Hendriks HJ, et al. Pelvic floor muscle training for urinary incontinence in women. Cochrane Database Syst Rev 2001;(1):CD001407.

25. Lorig KR, Sobel DS, Stewart AL, et al. Evidence suggesting that a chronic disease self-management program can improve health status while reducing hospitalization. Med Care 1999;37:5-14.

26. Gurden M, Morelli M, Sharp G, et al. Evaluation of a general practitioner referral service for manual treatment of back and neck pain. Prim Health Care Res Dev 2012;13:204-10.

27. Lorig K. Self-management of chronic illness: a model for the future. Generations 1993;17:11-14.

28. Lorig K. Self-management education: more than a NICE extra. Med Care 2003;41:699-701.

29. Lorig K, González VM, Laurent DD, et al. Arthritis self-management program variations: three studies. Arthritis Care Res 1998;11:448-54.

30. Lorig K, Holman $\mathrm{H}$. Arthritis self-management studies: a twelve-year review. Health Educ Q 1993;20:17-28.

31. Barlow J, Wright C, Sheasby J, et al. Self-management approaches for people with chronic conditions: a review. Patient Educ Couns 2002;48:177-87.

32. Barlow JH, Turner AP, Wright CC. A randomized controlled study of the arthritis self-management programme in the UK. Health Educ Res 2000;15:665-80.

33. Bourbeau J, van der Palen J. Promoting effective self-management programmes to improve COPD. Eur Respir J 2009;33:461-3.

34. Effing TW, Bourbeau J, Vercoulen J, et al. Self-management programmes for COPD: moving forward. Chron Respir Dis 2012;9:27-35.

35. Lennon S, McKenna S, Jones F. Self-management programmes for people post stroke: a systematic review. Clin Rehabil 2013;27:867-78.

36. Smith-Turchyn J, Morgan A, Richardson J. The effectiveness of group-based self-management programmes to improve physical and psychological outcomes in patients with cancer: a systematic review and meta-analysis of randomised controlled trials. Clin Oncol 2016;28:292-305.

37. Bishop M, Frain MP, Tschopp MK. Self-management, perceived control, and subjective quality of life in multiple sclerosis. Rehabil Couns Bull 2008;52:45-56.

38. Parsons MS. Self management support amongst older adults: the availability, impact and potential of locally based services and resources. School of Pharmacy, University of London, 2010.
39. Taylor SJC, Pinnock H, Epiphaniou E, et al. A rapid synthesis of the evidence on interventions supporting self-management for people with long-term conditions: PRISMS-Practical systematic review of self-management support for long-term conditions. Health Services and Delivery Research 2014;2:1-580.

40. Galdas P, Darwin Z, Fell J, et al. A systematic review and metaethnography to identify how effective, cost-effective, accessible and acceptable self-management support interventions are for men with long-term conditions (SELF-MAN). Health Services and Delivery Research 2015;3:1-302.

41. Mitteness LS. Knowledge and beliefs about urinary incontinence in adulthood and old age. J Am Geriatr Soc 1990;38:374-8.

42. Duralde ER, Walter LC, Van Den Eeden SK, et al. Bridging the gap: determinants of undiagnosed or untreated urinary incontinence in women. Am J Obstet Gynecol 2016;214:266.e1-9.

43. Nobili A, Garattini S, Mannucci PM. Multiple diseases and polypharmacy in the elderly: challenges for the internist of the third millennium. J Comorb 2011;1:28-44.

44. Dumoulin C, Cacciari LP, Hay-Smith EJC, et al. Pelvic floor muscle training versus no treatment, or inactive control treatments, for urinary incontinence in women. Cochrane Database Syst Rev 2018;56.

45. Wallace SA, Roe B, Williams $\mathrm{K}$, et al. Bladder training for urinary incontinence in adults. Cochrane Database Syst Rev 2004;6.

46. Rovner ES, Wein AJ. Treatment options for stress urinary incontinence. Rev Urol 2004;6:S29-S47.

47. Mercer SW, Gunn J, Bower P, et al. Managing patients with mental and physical multimorbidity. BMJ 2012;345.

48. Ontario $\mathrm{HQ}$. Behavioural interventions for urinary incontinence in community-dwelling seniors: an evidence-based analysis. Ont Health Technol Assess Ser 2008;8:1-52.

49. Tannenbaum C, Agnew R, Benedetti A, et al. Effectiveness of continence promotion for older women via community organisations: a cluster randomised trial. BMJ Open 2013;3:e004135.

50. Herbison P, Plevnik S, Mantle J. Weighted vaginal cones for urinary incontinence. Cochrane Database Syst Rev 2002;(1):CD002114.

51. Roe B, Williams K, Palmer M. Bladder training for urinary incontinence in adults. The Cochrane Library 2002.

52. Centre for Reviews and Dissemination. Systematic reviews: CRD's guidance for undertaking reviews in health care. University of York: University of York, Centre for Reviews \& Dissemination, 2009.

53. Liberati A, Altman DG, Tetzlaff J, et al. The PRISMA statement for reporting systematic reviews and meta-analyses of studies that evaluate health care interventions: explanation and elaboration. PLOS Med 2009;6:e1000100.

54. Moher D, Liberati A, Tetzlaff J, et al. Preferred reporting items for systematic reviews and meta-analyses: the PRISMA statement. PLOS Med 2009;6:e1000097.

55. Akobeng AK. Understanding randomised controlled trials. Arch Dis Child 2005;90:840-4.

56. Lim R, Liong ML, Leong WS, et al. Which outcome measures should be used in stress urinary incontinence trials? BJU Int 2018;121:805-10.

57. Higgins J, Green S. Cochrane handbook for systematic reviews of interventions Version 5.1.0 [updated March 2011]. The Cochrane Collaboration, 2011.

58. Reuters T. Endnote. New York: Thomson Reuters, 2011.

59. Higgins JPT, Altman DG, Gøtzsche PC, et al. The Cochrane Collaboration's tool for assessing risk of bias in randomised trials. BMJ 2011;343:d5928.

60. Khan KS, Ter Riet G, Glanville J, et al. Undertaking systematic reviews of research on effectiveness: CRD's guidance for carrying out or commissioning reviews. NHS Centre for Reviews and Dissemination, 2001

61. Popay J, Roberts H, Sowden A, et al. Guidance on the conduct of narrative synthesis in systematic reviews: a product from the ESRC methods programme. Version 1. Swindon: Economic and Social Research Council, 2006.

62. Hui E, Lee PSC, Woo J. Management of urinary incontinence in older women using videoconferencing versus conventional management: a randomized controlled trial. J Telemed Telecare 2006;12:343-7.

63. Kim H, Suzuki T, Yoshida Y, et al. Effectiveness of multidimensional exercises for the treatment of stress urinary incontinence in elderly community-dwelling Japanese women: a randomized, controlled, crossover trial. J Am Geriatr Soc 2007;55:1932-9.

64. Kim H, Yoshida H, Suzuki T. The effects of multidimensional exercise treatment on community-dwelling elderly Japanese women with stress, urge, and mixed urinary incontinence: a randomized controlled trial. Int J Nurs Stud 2011;48:1165-72. 
65. Leong BS, Mok NW. Effectiveness of a new standardised urinary continence physiotherapy programme for community-dwelling older women in Hong Kong. Hong Kong Med J 2015;21:30-7.

66. McFall SL, Yerkes AM, Cowan LD. Outcomes of a small group educational intervention for urinary incontinence: episodes of incontinence and other urinary symptoms. J Aging Health 2000;12:250-67.

67. Subak LL, Quesenberry CP, Posner SF, et al. The effect of behavioral therapy on urinary incontinence: a randomized controlled trial. Obstet Gynecol 2002;100:72-8.

68. Tannenbaum C, Fritel X, Halme A, et al. Long-Term effect of community-based continence promotion on urinary symptoms, falls and healthy active life expectancy among older women: cluster randomised trial. J Age Ageing 2019.

69. Andrade AD, Anam R, Karanam C, et al. An overactive bladder online self-management program with embedded avatars: a randomized controlled trial of efficacy. Urology 2015;85:561-7.

70. Burgio KL, Goode PS, Locher JL, et al. Behavioral training with and without biofeedback in the treatment of urge incontinence in older women: a randomized controlled trial. JAMA 2002;288:2293-9.

71. Burgio KL, Locher JL, Goode PS, et al. Behavioral vs drug treatment for urge urinary incontinence in older women: a randomized controlled trial. JAMA 1998;280:1995-2000.

72. Burns PA, Pranikoff K, Nochajski T, et al. Treatment of stress incontinence with pelvic floor exercises and biofeedback. J Am Geriatr Soc 1990;38:341-4.

73. Fantl JA, Wyman JF, McClish DK, et al. Efficacy of bladder training in older women with urinary incontinence. JAMA 1991;265:609-13.

74. Diokno AC, Newman DK, Low LK, et al. Effect of Group-Administered behavioral treatment on urinary incontinence in older women: a randomized clinical trial. JAMA Intern Med 2018;178:1333-41.

75. Aslan E, Komurcu N, Beji NK, et al. Bladder training and Kegel exercises for women with urinary complaints living in a rest home. Gerontology 2008:54:224-31.

76. Yalcin I, Patrick DL, Summers K, et al. Minimal clinically important differences in incontinence quality-of-life scores in stress urinary incontinence. Urology 2006;67:1304-8.

77. Simonsohn U, Nelson LD, Simmons JP. p-curve and effect size: correcting for publication bias using only significant results. Perspect Psychol Sci 2014;9:666-81.

78. Slieker-ten Hove M, Pool-Goudzwaard A, Eijkemans M, et al. Pelvic floor muscle function in a general population of women with and without pelvic organ prolapse. Int Urogynecol J 2010;21:311-9.

79. Henderson JW, Wang S, Egger MJ, et al. Can women correctly contract their pelvic floor muscles without formal instruction? Female Pelvic Med Reconstr Surg 2013;19:8-12.

80. Hay-Smith EJC, Herderschee R, Dumoulin C, et al. Comparisons of approaches to pelvic floor muscle training for urinary incontinence in women. Cochrane Database Syst Rev 2011;88.

81. Dworkin RH, Turk DC, Farrar JT, et al Core outcome measures for chronic pain clinical trials: IMMPACT recommendations. Pain 2005;113:9-19.
82. Abrams $\mathrm{P}$, Andersson $\mathrm{K}-\mathrm{E}$, Brubaker L, et al. 3Rd international consultation on incontinence recommendations of the International scientific Committee: evaluation and treatment of urinary incontinence, pelvic organ prolapse, and fecal incontinence Monaco: the scientific Committee of the International consultation on incontinence, 2005. Available: https://www.ics.org/Publications/ICl_ 3/v2.pdf/summary.pdf [Accessed 29th May 2019]

83. Center for Devices and Radiological Health. Clinical Investigations of Devices Indicated for the Treatment of Urinary Incontinence - Guidance for Industry and FDA Staff U.S: Food and Drug Administration, 2011. Available: https://www.fda.gov/media/71054/ download [Accessed 29th May 2019].

84. Coster WJ. Making the best match: selecting outcome measures for clinical trials and outcome studies. Am J Occup Ther 2013;67:162-70.

85. Labrie J, Berghmans BLCM, Fischer K, et al. Surgery versus physiotherapy for stress urinary incontinence. N Engl J Med 2013;369:1124-33.

86. Liu Z, Liu Y, Xu H, et al. Effect of electroacupuncture on urinary leakage among women with stress urinary incontinence: a randomized clinical trial. JAMA 2017;317:2493-501.

87. Dumoulin C, Hay-Smith J, Frawley H, et al. 2014 consensus statement on improving pelvic floor muscle training adherence: international continence Society 2011 State-of-the-Science seminar. Neurourol Urodyn 2015;34:600-5.

88. Alewijnse Det al. Predictors of long-term adherence to pelvic floor muscle exercise therapy among women with urinary incontinence. Health Educ Res 2003;18:511-24.

89. Campbell SE, Glazener CM, Hunter KF, et al. Conservative management for postprostatectomy urinary incontinence. Cochrane Database Syst Rev 2012;1.

90. Burgio KL, Goode PS, Richter HE, et al. Global ratings of patient satisfaction and perceptions of improvement with treatment for urinary incontinence: validation of three global patient ratings. Neurourol Urodyn 2006;25:411-7.

91. Boger E, Ellis J, Latter S, et al. Self-Management and selfmanagement support outcomes: a systematic review and mixed research synthesis of Stakeholder views. PLoS One 2015;10:e0130990.

92. Grady PA, Gough LL. Self-Management: a comprehensive approach to management of chronic conditions. Am J Public Health 2014:104:e25-31.

93. Orrell A, McKee K, Dahlberg L, et al. Improving continence services for older people from the service-providers' perspective: a qualitative interview study. BMJ Open 2013;3:e002926.

94. Landefeld CS, Bowers BJ, Feld AD, et al. National Institutes of health state-of-the-science conference statement: prevention of fecal and urinary incontinence in adults. Ann Intern Med 2008; $148: 449-58$

95. Ioannidis JPA. Why most published research findings are false. PLoS Med 2005;2:e124. 
Correction: Multifaceted self-management interventions for older women with urinary incontinence: a systematic review and narrative synthesis

Fu Y, Nelson EA, McGowan L. Multifaceted self-management interventions for older women with urinary incontinence: a systematic review and narrative synthesis. BMJ Open 2019;9:e028626. doi: 10.1136/bmjopen-2018-028626

This article was previously published with below errors.

- The second sentence of results under abstract section was incorrect. The correct sentence is 'There was only one study rated as of high quality'.

- Please find the below list of corrections made in table 2:

\begin{tabular}{|c|c|}
\hline Orginial & Corrections made \\
\hline $\mathrm{RR}=6.19,(0.80$ to 48.02$) \dagger$ & $\mathrm{RR}=6.19,(0.80$ to 48.02$) \ddagger$ \\
\hline$M D=-10.00,(-13.89$ to 6.11$) \dagger \ddagger$ & $M D=-10.00,(-13.89$ to -6.11$) \dagger \ddagger$ \\
\hline$M D=0.10,(-0.09$ to 029$) \dagger$ & $\mathrm{MD}=0.10,(-0.09$ to 029$) \ddagger$ \\
\hline $\mathrm{RR}=6.00,(2.91$ to 12.35$) \dagger \ddagger$ & $\mathrm{RR}=6.00,(2.91$ to 12.35$) \dagger \S$ \\
\hline $\mathrm{MD}=-0.91,(-1.59$ to 0.23$) \S$ & $\mathrm{MD}=-0.91,(-1.59$ to -0.23$) \dagger \S$ \\
\hline $\mathrm{MD}=-6.40,(-8.81$ to 3.99$) \dagger \ddagger \S$ & $\mathrm{MD}=-6.40,(-8.81$ to -3.99$)+\emptyset$ \\
\hline$M D=11.38,(1.78$ to 20.98$) \dagger \ddagger \S$ & $\mathrm{MD}=11.38 .(1.78$ to 20.98$)+9$ \\
\hline$M D=-5.80,(-10.61$ to 0.99$) \dagger \ddagger$ & $M D=-5.80,(-10.61$ to -0.99$) \dagger \ddagger$ \\
\hline \#: primary outcome was not defined & *primary outcome was not defined. \\
\hline *: significance at $95 \%$ & $\dagger$ : significance at $95 \%$. \\
\hline +: per protocol analysis & łper protocol analysis. \\
\hline ‡: intention to treat; & §intention to treat. \\
\hline +\#: no loss to follow-up or dropout & Ino loss to follow-up or dropout. \\
\hline
\end{tabular}

The corrected version of table 2 is:

Table 2 Effect size of the intervention for the primary outcome (grouped by intervention type)

\begin{tabular}{|c|c|c|c|}
\hline Study, year & Intervention type & Primary outcome & $\begin{array}{l}\text { Effect size (intervention } \\
\text { vs control), } 95 \% \mathrm{Cl}\end{array}$ \\
\hline Burns et al (1990) & PFME related & Cure of UI episodes* & $\begin{array}{l}\text { Biofeedback } \\
\text { RR=8.55,(1.14 to } 63.31) \dagger \ddagger \\
\text { Without biofeedback } \\
R R=6.19,(0.80 \text { to } 48.02) \ddagger\end{array}$ \\
\hline Kim et al (2007) & PFME related & $\begin{array}{l}\text { The number of Ul episodes } \\
\text { in } 3 \text { days; cured defined as } \\
\text { episodes disappeared }\end{array}$ & $\mathrm{RR}=5.82,(1.90$ to 17.86$) \dagger \ddagger$ \\
\hline Kim et al (2011) & PFME related & Cure rate of UI episodes & $\begin{array}{l}\mathrm{RR}=26.88,(3.77 \text { to } \\
191.79) \dagger \neq\end{array}$ \\
\hline Fantl et al (1991) & $\begin{array}{l}\text { Bladder retraining } \\
\text { related }\end{array}$ & $\begin{array}{l}\text { The number of } \mathrm{UI} \text { episodes in } \\
7 \text { days }\end{array}$ & $\begin{array}{l}M D=-10.00,(-13.89 \text { to } \\
-6.11) \dagger \ddagger\end{array}$ \\
\hline Hu et al (1990) & $\begin{array}{l}\text { Bladder retraining } \\
\text { related }\end{array}$ & $\begin{array}{l}\text { The change in the number of UI } \\
\text { episodes daily }\end{array}$ & $\mathrm{MD}=-0.25(-0.75$ to 0.25$) \ddagger$ \\
\hline $\begin{array}{l}\text { Dougherty et al } \\
\text { (2002) }\end{array}$ & $\begin{array}{l}\text { Behavioural training } \\
\text { (PFME, lifestyle } \\
\text { modification, bladder } \\
\text { retraining) }\end{array}$ & Urine loss (g) per pad test & $\begin{array}{l}M D=1.00,(-28.91 \text { to } \\
30.91) \S\end{array}$ \\
\hline Hui et al (2006) & $\begin{array}{l}\text { Behavioural training } \\
\text { (PFME, lifestyle } \\
\text { modification, } \\
\text { education) }\end{array}$ & $\begin{array}{l}\text { The number of UI episodes } \\
\text { daily* }^{*}\end{array}$ & $\mathrm{MD}=0.10,(-0.09$ to 029$) \ddagger$ \\
\hline
\end{tabular}




\begin{tabular}{|c|c|c|c|}
\hline Study, year & Intervention type & Primary outcome & $\begin{array}{l}\text { Effect size (intervention } \\
\text { vs control), } 95 \% \mathrm{Cl}\end{array}$ \\
\hline $\begin{array}{l}\text { Tannenbaum et al } \\
\text { (2013) }\end{array}$ & $\begin{array}{l}\text { Behavioural training } \\
\text { (PFME, lifestyle } \\
\text { modification, } \\
\text { education) }\end{array}$ & $\begin{array}{l}\text { Self-reported improvement in } \\
\text { incontinence }\end{array}$ & $\begin{array}{l}R R=5.40,(2.66 \text { to } 10.97) \dagger \ddagger \\
R R=6.00,(2.91 \text { to } 12.35) \dagger \S\end{array}$ \\
\hline $\begin{array}{l}\text { Tannenbaum et al } \\
\text { (2019) }\end{array}$ & $\begin{array}{l}\text { Behavioural training } \\
\text { (PFME, lifestyle } \\
\text { modification, } \\
\text { education) }\end{array}$ & $\begin{array}{l}\text { self-reported improvement in } \\
\text { incontinence at } 1 \text { year }\end{array}$ & $\mathrm{RR}=1.81,(1.44$ to 2.27$) \dagger \S$ \\
\hline Aslan et al (2008) & $\begin{array}{l}\text { Behavioural training } \\
\text { (PFME, bladder } \\
\text { retraining, education) }\end{array}$ & $\begin{array}{l}\text { Reduction in the number of UI } \\
\text { episodes in } 7 \text { days* }\end{array}$ & $\mathrm{RR}=5.33,(1.77$ to 16.05$) \dagger \ddagger$ \\
\hline $\begin{array}{l}\text { Diokno et al } \\
(2018)\end{array}$ & $\begin{array}{l}\text { Behavioural training } \\
\text { (PFME, bladder } \\
\text { retraining, education) }\end{array}$ & $\begin{array}{l}\text { Ul symptoms (measured by the } \\
\text { International Consultation on } \\
\text { Incontinence Questionnaire - } \\
\text { short form) }\end{array}$ & $\begin{array}{l}M D=-0.91,(-1.59 \text { to } \\
-0.23) \dagger \S\end{array}$ \\
\hline Leong et al (2015) & $\begin{array}{l}\text { Behavioural training } \\
\text { (PFME, bladder } \\
\text { retraining, education) }\end{array}$ & $\begin{array}{l}\text { The number of } \mathrm{UI} \text { episodes in } \\
7 \text { days }\end{array}$ & $\begin{array}{l}M D=-6.40,(-8.81 \text { to } \\
-3.99)+9\end{array}$ \\
\hline $\begin{array}{l}\text { Andrade et al } \\
(2015)\end{array}$ & $\begin{array}{l}\text { Behavioural training } \\
\text { (PFME, bladder } \\
\text { retraining, review } \\
\text { session, education) }\end{array}$ & $\begin{array}{l}\text { Health-related quality of life } \\
\text { (measured by the Overactive } \\
\text { bladder Health-related Quality } \\
\text { of Life) }\end{array}$ & $\begin{array}{l}\mathrm{MD}=11.38 .(1.78 \text { to } \\
20.98)+\emptyset\end{array}$ \\
\hline $\begin{array}{l}\text { Burgio et al } \\
\text { (1998) }\end{array}$ & $\begin{array}{l}\text { Behavioural training } \\
\text { (PFME, bladder } \\
\text { retraining, review } \\
\text { session, education) }\end{array}$ & $\begin{array}{l}\text { Reduction\% in the number of UI } \\
\text { episodes }\end{array}$ & $\begin{array}{l}M D=41.30,(20.47 \text { to } \\
62.13) \dagger \S\end{array}$ \\
\hline $\begin{array}{l}\text { Burgio et al } \\
(2002)\end{array}$ & $\begin{array}{l}\text { Behavioural training } \\
\text { (PFME, bladder } \\
\text { retraining, review } \\
\text { session, education) }\end{array}$ & $\begin{array}{l}\text { Reduction\% in the number of UI } \\
\text { episodes }\end{array}$ & $\begin{array}{l}\text { Biofeedback: } \\
\text { MD=4.50,(-8.66 to } 17.66) \S \\
\text { Verbal feedback: } \\
\text { MD=10.80,(-0.94 to } \\
22.54) \S\end{array}$ \\
\hline $\begin{array}{l}\text { McFall et al } \\
(2000)\end{array}$ & $\begin{array}{l}\text { Behavioural training } \\
\text { (PFME, bladder } \\
\text { retraining, review } \\
\text { session, education) }\end{array}$ & $\begin{array}{l}\text { The number of UI episodes in } \\
7 \text { days }^{*}\end{array}$ & $\mathrm{MD}=-2.35,(-5.30$ to 0.60$) \neq$ \\
\hline Subak et al (2002) & $\begin{array}{l}\text { Behavioural training } \\
\text { (PFME, bladder } \\
\text { retraining, review } \\
\text { session, education) }\end{array}$ & $\begin{array}{l}\text { The number of UI episodes in } \\
7 \text { days }\end{array}$ & $\begin{array}{l}M D=-5.80,(-10.61 \text { to } \\
-0.99) \dagger \ddagger\end{array}$ \\
\hline
\end{tabular}

*primary outcome was not defined.

$\dagger$ : significance at $95 \%$.

łper protocol analysis.

§intention to treat.

Ino loss to follow-up or dropout.

PFME, pelvic floor muscle exercise; UI, urinary incontinence; RR, risk ratio; MD, mean difference.

Open access This is an open access article distributed in accordance with the Creative Commons Attribution Non Commercial (CC BY-NC 4.0) license, which permits others to distribute, remix, adapt, build upon this work non-commercially, and license their derivative works on different terms, provided the original work is properly cited, appropriate credit is given, any changes made indicated, and the use is non-commercial. See: http://creativecommons.org/licenses/by-nc/4.0/.

(c) Author(s) (or their employer(s)) [year]. Re-use permitted under CC BY-NC. No commercial re-use. See rights and permissions. Published by BMJ.

BMJ Open 2019;9:e028626. doi:10.1136/bmjopen-2018-028626corr1

Check for updates 